\title{
Editorial
}

\section{The Triple Helix Model and the Future of Innovation: A Reflection on the Triple Helix Research Agenda}

\section{Introduction}

Based on their early explorations on new perspectives on the role of academia and organised knowledge production in regional innovation, Etzkowitz and Leydesdorfff had consolidated the Triple Helix concept through either collaborative works (e.g. Etzkowitz \& Leydesdorff, 1995, 2000) or individual publications (e.g. Etzkowitz, 2008; Leydesdorff, 2000). They developed the Triple Helix model to explain the dynamic interactions between academia, industry, and government that foster entrepreneurship, innovation, and economic growth in a knowledge-based economy (Etzkowitz \& Leydesdorff, 2000). In research communities, there are continuous efforts to apply/enhance the Triple Helix model as well as criticisms on its limits or limitations. Probably, there is no other place more suitable than the Triple Helix journal, which bears the model's name, to play the role of provoking discussions on the Triple Helix model, especially for understanding the future of innovation in society.

While our initial plan was to write a short editorial to introduce the special issue on the theme 'the Triple Helix model and the future of innovation', we have decided to include our Editors-in-Chiefs' reflection on the Triple Helix research agenda for two reasons. First, reading the articles collected in the special issue reminds us that those researchers involved in Triple Helix studies not only deal with the Triple Helix concept itself but also engage with the concepts either embedded in or derived from it. Thus, one may wonder: What are the core concepts within the umbrella of Triple Helix? Second, while the articles, in the special issue and also in the journal, deal with a wide range of themes in 
different sectors of the society related to innovation, we asked ourselves: Can the Triple Helix model be applied to deal with 'everything' or, if not, what are the boundary conditions? This question is linked to an ongoing debate regarding the model's usefulness for understanding the dynamics of innovation in a changing society (Cai \& Lattu, 2021). Thus, before we introduce the articles included in the special issue, we will address the two concerns of editors and probably many others in the Triple Helix research community.

\section{Concepts under the Umbrella of Triple Helix}

Sometimes, the Triple Helix model is narrowly understood as a metaphor for the relationship between university, industry, and government. Indeed, this is a good metaphor, but more important is the theoretical rationale underlying the metaphor. For instance, Cai and Etzkowitz (2020) make explicit the five triple helix mechanisms. When reading the classic works of Etzkowitz and Leydesdorff on Triple Helix, one should notice several related concepts, such as spheres, spaces, functions, entrepreneurial universities, and academic revolutions. For instance, a literature review project led by Marcelo Amaral (Co-Editor-in-Chief of the journal) at the Triple Helix Research Group, Fluminense Federal University, consider how explicit these concepts are applied as a critical criterion to identify Triple Helix studies. Lacking a comprehensive understanding of these concepts, which are important parts of the Triple Helix thesis, often leads to misunderstanding and misusing the Triple Helix model in empirical studies (Cai \& Lattu, 2021). Next, we briefly introduce the concepts associated with the Triple Helix model.

\section{Entrepreneurial University}

The entrepreneurial university and Triple Helix model are two closely interrelated concepts. One prerequisite of the Triple Helix model is that 'the university's enhanced relevance to technology transfer, firm-formation and regional renewal places it in a primary position in knowledge-based society in contrast to its secondary role in industrial society' (Cai \& Etzkowitz, 2020, p. 195). Etzkowitz's thinking related to the Triple Helix model started from his conceptualisation of entrepreneurial university, initially labelled entrepreneurial science (Etzkowitz, 1983). The entrepreneurial university concept was further developed along with Etzkowitz and Leydesdorff's elaboration of the Triple Helix model. Etzkowitz (2004) proposed five principles/propositions of the entrepreneurial university concerning 1) Capitalisation, 2) Interdependency, 3) Independence, 4) Hybridisation, and 5) Reflexivity. In the second edition of 
The Triple Helix book, Etzkowitz and Zhou (2017) renewed the propositions in terms of five norms of the entrepreneurial university model, namely 1) Knowledge spilled-over, 2) Hybridisation, 3) Units as quasi-firms, 4) Entrepreneurial culture, and 5) Reflexivity. It should be mentioned that Clark (1998) and Röpke (1998) also proposed the entrepreneurial university concept in the same period. They shared similar views with Etzkowitz on the major characteristics of an entrepreneurial university (Etzkowitz et al., 2017).

\section{Academic Revolutions}

Accompanied with the notion of an entrepreneurial university is the concept of academic revolutions. Before the model of Triple Helix was coined in 1995, Etzkowitz (1990) stressed that the second academic revolution is an essential concept for understanding the changing landscape of higher education in the knowledge-based society. His idea of the second academic revolution is in line with and complementary to the concept of scientific revolutions (Kuhn, 2012) and technical-economic paradigms (Perez, 2010). While the Humboldtian model of integrating research and teaching in universities represents the first academic revolution, the second academic revolution concerns the strengthened economic role of universities. As such, universities are demanded to be entrepreneurial. In such a context, several related concepts emerged, such as the third mission (Etzkowitz, 1994), academic capitalism (Slaughter \& Leslie, 1997), and the mode II knowledge production (Gibbons et al., 1994). The third mission disrupts universities' traditional teaching and research trajectories and drives universities to seek reciprocal relationships with stakeholders, e.g., in industry and government. As suggested by Etzkowitz (2008, p. 8), 'a Triple Helix regime typically begins as university, industry, and government enters into a reciprocal relationship with each other in which each attempts to enhance the performance of the other'. Later, Etzkowitz and Viale (2010) drew attention to the third-round academic revolution that emphasises the vital role of universities in social transformation. They argued that both the second and third academic revolutions simultaneously take place in a Triple Helix.

\section{Spheres, Spaces and Functions}

Another three concepts are essential for understanding the triple helix interactions, namely spheres, spaces, and functions. Spheres are exchangeable with helices, referring to university, industry and government (Etzkowitz, 2008; Etzkowitz \& Leydesdorff, 1995). The notion 'sphere' is borrowed from the ideas of some economists (e.g. Kalecki, 1954; Marshall, 1960), who use the same concept to categorise economic actors from different industrial sectors. What distinguishes Etzkowitz \& Leydesdorff' s approach from the economists' interests 
in spheres lies in their emphasis on the interactions/relations between the spheres. While Etzkowitz and Leydesdorff jointly developed the Triple Helix model with a shared understanding of synergy building among the three spheres/helices, they have further elaborated on the mechanisms of Triple Helix interactions from a neo-institutional perspective and a neo-evolutionary perspective, respectively (Leydesdorff, 2012). The former perspective emphasises the relations between the three spheres. To better account for the mechanisms of Triple Helix interactions, the concepts of knowledge, consensus and innovation spaces were developed (Etzkowitz, 2008; Etzkowitz \& Zhou, 2017). The latter perspective considers that the three helices also operate 'as selection mechanisms asymmetrically on one another, but mutual selections may shape a trajectory as in a coevolution' (Leydesdorff, 2012, p. 28). In such a lens, the Triple Helix is perceived as three functions - namely, wealth creation, knowledge production, and normative control (Leydesdorff, 2012).

\section{Boundaries of Applying the Triple Helix Model}

Every social science theory has its explanatory power as well as its limits. When using the Triple Helix model in empirical studies, one must know in what situations the model is more effective and in what conditions not; in between are the boundaries. Here, we highlight what are within the boundaries in terms of both the scope of analysis and the explanatory power of Triple Helix. Understanding where Triple Helix is more useful in innovation analysis makes one more likely to notice the model's limitations.

\section{Boundaries in Terms of Analysis Scope}

The Triple Helix as a model of innovation primarily conceptualises the dynamics of innovation at the societal level. In this sense, it is similar to other analytical tools, such as the innovation system. The Triple Helix model and the innovation system approach differ due to their separate theoretical roots, namely the general system theory and Simmel's triadic interactions (Cai \& Lattu, 2021). Etzkowitz and Zhou (2017) contrasted the two concepts in 10 dimensions. We want to highlight that the Triple Helix is likely to be more effective than the innovation system concept when the analyses focus on 1) How the system-level innovation is organised, and 2) How the dynamic in the system can be measured. The efficacy of Triple Helix analysis on the two aspects is due to some unique insights of the Triple Helix thesis. First, the Triple Helix model requires an organised acceleration process and innovation organisers, which is in contract with the innovation system's assumption that a 
system of innovation is expected to evolve through self-organisation (Etzkowitz \& Zhou, 2017). Second, using the Triple Helix, 'one can measure the extent to which innovation has become systemic instead of assuming the existence of national (or regional) systems of innovations on prior grounds'(Leydesdorff, 2012, p. 25).

The Triple Helix is effective in understanding the dynamics of innovation at the regional, national or international level, as it provides a well-elaborated framework for understanding central inquires in innovation processes, including 1) What are the key actors; 2) What are the mechanisms of interactions between the actors; 3) What are the enabling conditions of the interactions.

Regarding the key actors, the Triple Helix model focuses on university, industry, and government. However, it does not exclude other actors, such as intermediaries, legal firms and non-governmental agencies, but consider them secondary players (Cai \& Etzkowitz, 2020). Indeed in each of the spheres of university, industry and government, there are 'a wide array of actors, among whom a distinction is made between: (a) individual and institutional innovators; (b) R\&D and non-R\&D innovators; and (c) "single-sphere" and "multisphere” (hybrid) institutions' (Ranga \& Etzkowitz, 2013, p. 238).

The mechanism of Triple Helix interaction is "taking the role of the other" (Etzkowitz, 2008), performing new while maintaining their traditional function.

Organisations taking non-traditional roles are viewed as a major potential source of innovation in innovation. For instance, firms continue to produce goods and services, but also do research and provide training at high levels (e.g., through the corporate university). The government is responsible for resolving market failures, adjusting public policies and establishing market rules, but also makes available venture capital to start new enterprises, particularly for high-risk businesses. Universities keep their traditional roles of teaching and research, but also devote effort to the capitalisation of knowledge, patents, and start-up companies.

CAI \& ETZKOWITZ, 2O2O, p. 203

The Triple Helix model can only be expected when certain conditions are met. Etzkowitz originally suggested both sufficient and necessary conditions that enable the Triple Helix. The sufficient condition of convening authority concerns the actions of political authorities to convene the representatives of the three helices to address innovation gaps (Etzkowitz, 1993, 2002). The necessary condition of innovation capacity refers to the ability to create a knowledge base with commercialisation potential (Ranga \& Etzkowitz, 2013). Cai (2014, 2015) further identified seven institutional logics as intangible conditions 
enabling an ideal type of Triple Helix model. It must be stressed that civil society is not absent in the Triple Helix model, as some researchers might misunderstand (Cai \& Lattu, 2021). Instead, civil society has been considered 'the launch pad for take-off triple helix interactions' (Etzkowitz, 2014, p. 19) or an institutional ground of the Triple Helix (Cai, 2015). Leydesdorff (2012, p. 30) put it, 'the [triple] helices represent specialisation and codification in function systems which evolve from and within civil society'.

The Triple Helix thesis about the three core issues mentioned above is also reflected in the ten propositions (Etzkowitz, 2003) and five rationales (Cai \& Etzkowitz, 2020) of Triple Helix, respectively. Its theoretical foundations have been continuously strengthened by both the founders of the concept and those as a new generation of Triple Helix researchers (Cai \& Etzkowitz, 2020).

Moreover, the Triple Helix model has also been designed for analysing transformations and dynamics within each of the Helices. The Triple Helix thesis also provides separate concepts/frames to understand the nature of university, industry and government in a Triple Helix.

First, both the notions of an entrepreneurial university and second/third academic revolutions address the transformations in universities. In this regard, the Triple Helix model can serve as a useful tool to analyse the process of capitalisation of knowledge (Etzkowitz, 2011b; Etzkowitz \& Goktepe-Hulten, 2010) as well as mechanisms underlying and infrastructures supporting the process (Etzkowitz, 2011a; Etzkowitz \& Zhou, 2017; Piqué, Berbegal-Mirabent, \& Etzkowitz, 2020). The characteristics of the entrepreneurial university model can be grasped by the five norms (Etzkowitz \& Zhou, 2017), updated from the five propositions of an entrepreneurial university (Etzkowitz, 2004), as mentioned above. Recently, Etzkowitz developed 12-dimension categories for comparing traditional ivory-tower universities and entrepreneurial universities (Etzkowitz, 2017; Etzkowitz et al., 2019).

Second, concerning the transformation in the industry sector, Etzkowitz and Zhou (2017) use the concept 'triple helix firm' to describe the boundaryspanning nature of firms in a Triple Helix. The firms are hybrid entities, 'combining triple helix elements of the public and private to various degrees, with multiple investors, stakeholders or shareholders' (Etzkowitz \& Zhou, 2017, p. 80). Such knowledge-based firms can be formed under ten conditions concerning human capital, material, and organisational factors, respectively (ibid.).

Third, the Triple Helix provides a unique lens to see government not only as a regulator but as an active agent also. The public venture concept is used to understand the state's role (Etzkowitz \& Gulbrandsen, 1999). According to Etzkowitz and Zhou (2017), the optimal role of government can be best 
performed in an 'innovation state' that attempts to regenerate the sources of productivity in science and technology through new forms of cooperative relations. They further proposed five propositions about the transformation of traditional state functions to promote innovation. The empirical studies have approved the usefulness of Triple Helix in analysing governance and coordination of innovation processes, such as translating knowledge into technology and innovation (Amaral, 2015; Olvera, Piqué, Cortés, \& Nemirovsky, 2020). The Triple Helix perspective could be advantageous when there has been increasing consensus regarding the relevance of state intervention in societal and economic development, after the financial and economic crisis in 2008 and especially the recent catastrophe caused by Covid-19.

\section{Boundaries in Terms of Explanatory Power}

In a very recent article, Cai and Lattu (2021) systematically examined the strengths and weaknesses of the Triple Helix model (as well as the Quadruple Helix model) for understanding innovation dynamics in innovation ecosystems that represent the contemporary or future society. They identified the (changing) features in innovation ecosystems in three dimensions compared to those in innovation systems. First, the model of knowledge production is shifting from mode 2 to mode 3. Second, key players in innovation processes are becoming more diverse and interdependent. The third dimension is about changes in the social context, which are seen from both temporal and spatial perspectives. In the temporal context, innovation must be sustainable, and actors involved in the innovation process are required to be responsible for future generations. In the spatial dimension, innovation processes occur in the context of globalisation, the cornerstone of which has shifted from countries and organisations to individuals.

Cai and Lattu (2021) concluded that although the Triple Helix model was originated in the 199os when some pioneer nations had just begun their strategies for developing innovation systems, its theoretical core can or have the potential to analyse interactions and synergy building among actors in innovation ecosystems. However, they also reminded that the new features in innovation ecosystems, as mentioned above, have not been explicitly addressed in the theoretical elaboration of the model. For instance, it has been argued that the Triple Helix model was mainly based on Modes 1 and 2 of knowledge production (Carayannis \& Campbell, 20o9). However, Triple Helix scholars have constantly been developing the theoretical foundations of the Triple Helix model, with attempts to capture the dynamics of sustainable innovation in contemporary society (Cai \& Etzkowitz, 2020). For example, Cai and Ahmad 
(2021) proposed and conceptualised a sustainable entrepreneurial university to respond to the demands arising from the transformation from innovation systems to innovation ecosystems for a renewed understanding of the nature of universities and their roles in society.

The explanatory power of Triple Helix is also reinforced by the efforts to develop Triple Helix indicators (Leydesdorff \& Park, 2014). Leydesdorff (2003) and Leydesdorff and Meyer (2003) initially introduced a scientometric measurement of Triple Helix dynamics. For instance, entropy and synergy concepts are applied in Triple Helix measurements using patents and other statistical information as data (Ivanova, Strand, Kushnir, \& Leydesdorff, 2015; Leydesdorff, 2008). This idea makes sense for codified knowledge in the most advanced economies, but its application in the least developed economies is complex due to the low level of codification. Leydesdorff (2012) also warned that the existence of the Triple Helix actors and the linkages among them does not necessarily mean that the result of these interactions will be positive in terms of knowledge generation, innovation, and entrepreneurship. It is related to one of the misunderstandings of the Triple Helix model: Triple Helix interactions are equal to collaborative relations within tri-lateral networks (Cai \& Lattu, 2021). Thus, we argue that the important but challenging task could be to identify and develop indicators to capture the mechanism of 'taking the role of the other'. Only when such mechanism exists in the tri-lateral networks, innovation and entrepreneurship are likely to occur (Etzkowitz, 2008).

\section{The Articles in the Special Issue}

While the four articles collected in the special issue all deal with the future of innovation and the entrepreneurial university, they also show the diversity of Triple Helix analysis. These studies engage with different concepts/approaches of Triple Helix and help understand the boundaries of Triple Helix analysis.

In the first article, Rothgang and Lageman (2021) introduce a new concept, 'Kairos constellation', to supplement the theoretical foundations of the Triple Helix model. A Kairos constellation designates a temporary opportunity for a group of actors to take advantage of a coincidence of favourable circumstances to realise a shared target. While Kairos constellations may frequently occur in triple helix interactions, such a phenomenon has not been explicitly theorised by Triple Helix. Thus, the authors try to provide a theoretical account of Kairos constellations and hope this could provide helpful guidance on taking full advantage of a Kairos moment while overcoming potential risks for those actors involved in the Kairos constellations. 
In the second article, Virkkala and Mariussen (2021) propose a new method of measuring how various innovation networks can create different types of complex synergies based on first-hand data. It is called connectivity analysis. Such a measurement is different from the existing approaches in two aspects. First, while the current methods mainly measure synergies of cooperation between university, industry, and government at the macro level, the authors look at individual actors, particularly their networks, in their Triple Helix measurement. Second, the authors use first-hand data collected through surveys/ interviews for their measurement, which contrasts the existing methods that mainly use patent data, firm data, and other secondary statistical sources. Their approach helps measure more complex synergies because it not only examines the interactions between networks from different helices but also discerns the variation among organisations and networks in the same helix as well as the types of networks (e.g., weak or strong).

In the third article, Malik, Kabiraj, and Huo (2021) quantitatively explore how universities' density in a city moderates foreign/domestic direct investments' contribution to local innovation in the ICT sector in the Chinese context. Their analysis shows that the population of universities in a city positively moderates the relation between these investments and the city's development level. The findings shed light on the Triple Helix thesis in two ways. First, it suggests that the populations of universities are among enabling conditions of Triple Helix. Second, it evidences and conceptualises universities' role in mobilising resources for enlarging innovation effects.

In the last article, Abisuga and Muchie (2021) propose a conceptual model that describes Arts Entrepreneurship Education (AEE). Scholars have highlighted the need for more explicit knowledge, conceptualisation, and theorising on the practicality of integrating arts entrepreneurship education in university programs. This research paper fills the existing gap in the literature on the AEE and argues that if entrepreneurship is to be viewed as a fundamental part of AEE, teachers need to properly know the importance and inclusion in the University's art subject curriculum.

Yuzhuo Cai

Tampere University, Co-Editor-in-Chief of Triple Helix

Marcelo Amaral

Fluminense Federal University, Co-Editor-in-Chief of Triple Helix 


\section{References}

Abisuga, O. A., \& Muchie, M. (2021). Development of Arts Entrepreneurship Education: Excavating and Unravelling the Knowledge Basis. Triple Helix, 1-29. doi:10.1163/21971927-bja1oo14.

Amaral, M. (2015). Management and assessment of innovation environments. Triple Helix, 2(1), 19. doi:10.1186/s406o4-015-0030-5.

Cai, Y. (2014). Implementing the Triple Helix model in a non-Western context: an institutional logics perspective. Triple Helix, 1(1), 1-20. doi:10.1186/s406o4-014-00o1-2

Cai, Y. (2015). What contextual factors shape "innovation in innovation"? - Integration of insights of the Triple Helix and the institutional logics perspective. Social Science Information, 54(3), 299-326. doi:10.1177/0539018415583527.

Cai, Y., \& Ahmad, I. (2021). From an Entrepreneurial University to a Sustainable Entrepreneurial University: Conceptualisation and Evidence in the Contexts of European University Reforms. Higher Education Policy. doi:10.1057/s41307-021-00243-z.

Cai, Y., \& Etzkowitz, H. (2020). Theorising the Triple Helix model: Past, present, and future. Triple Helix, 7(2-3), 189-226. doi:https://doi.org/10.1163/21971927-bja1ooo3

Cai, Y., \& Lattu, A. (2021). Triple Helix or Quadruple Helix: Which model of innovation to choose for empirical studies? . Minerva. doi:https://doi.org/10.1007/s11024 -o21-09453-6.

Carayannis, E. G., \& Campbell, D. F. J. (2009). "Mode 3" and "Quadruple helix": toward a 21st century fractal innovation ecosystem. International Journal of Technology Management, 46(3/4), 201-234.

Clark, B. R. (1998). Creating entrepreneurial universities: organisational pathways of transformation. New York: Pergamon.

Etzkowitz, H. (1983). Entrepreneurial scientists and entrepreneurial universities in American academic science. Minerva, 21 (2-3), 198-233.

Etzkowitz, H. (1990). The Second Academic Revolution: The Role of the Research University in Economic Development. In S. Cozzens, P. Healey, A. Rip, \& J. Ziman (Eds.), The Research System in Transition (Vol. 57, pp. 109-124): Springer Netherlands.

Etzkowitz, H. (1993). Technology transfer: the second academic revolution. Technology Access Report, 6, 7-9.

Etzkowitz, H. (2002). Incubation of incubators: innovation as a triple helix of university-industry-government networks. Science and Public Policy, 29(2), 115-128. doi:10.3152/147154302781781056.

Etzkowitz, H. (2003). Innovation in innovation: the triple helix of university-industrygovernment relations. Social Science Information, 42(3), 293-337.

Etzkowitz, H. (2004). The evolution of the entrepreneurial university. International Journal of Technology and Globalisation, 1(1), 64-77. Retrieved from http://inderscience.metapress.com/content/VFP 58 MEACN34AXNM. 
Etzkowitz, H. (2008). The triple helix: university-industry-government innovation in action. New York ; London: Routledge.

Etzkowitz, H. (2011a). Special Introduction: Convergence of Science Parks, Centres and Clusters: From Creative Destruction to Creative Reconstruction in a Triple Helix Regime. International Journal of Technoentrepreneurship, 2(3/4).

Etzkowitz, H. (2011b, 11-14, July). Stanford and Silicon Valley: The Co-Evolution of Technology Transfer and Regional Absorptive Capacity, 1930-2005. Paper presented at the Triple Helix Ix International Conference: "Silicon Valley: Global Model or Unique Anomaly?".

Etzkowitz, H. (2014). Making a humanities town: knowledge-infused clusters, civic entrepreneurship and civil society in local innovation systems. Triple Helix, 1(1), 1. doi:10.1186/s406o4-014-0012-z.

Etzkowitz, H. (2017). Innovation Lodestar: The entrepreneurial university in a stellar knowledge firmament. Technological Forecasting and Social Change, 123, 122-129. doi:https://doi.org/10.1016/j.techfore.2016.04.026.

Etzkowitz, H., Bikkulov, A., Kovaleinen, A., Leitner, K. H., Poutanen, S., Grey, D., . . . Cai, Y. (2017). Metrics for the Entrepreneurial University. Triple Helix Working Papers, 2017 (1). Retrieved from https:/www.triplehelixassociation.org/working-papers/ metrics-for-the-entrepreneurial-university.

Etzkowitz, H., Germain-Alamartine, E., Keel, J., Kumar, C., Smith, K. N., \& Albats, E. (2019). Entrepreneurial university dynamics: Structured ambivalence, relative deprivation and institution-formation in the Stanford innovation system. Technological Forecasting and Social Change, 141, 159-171. doi:https://doi.org/10.1016/j .techfore.2018.10.019.

Etzkowitz, H., \& Goktepe-Hulten, D. (2010). Maybe they can? University technology transfer offices as regional growth engines. International Journal of Technology Transfer and Commercialisation, 9(1-2), 166-181. doi:10.1504/ijttc.2010.029431.

Etzkowitz, H., \& Gulbrandsen, M. (1999). Public entrepreneur: the trajectory of United States science, technology and industrial policy. Science and Public Policy, 26(1), 53-62. doi:10.3152/147154399781782590.

Etzkowitz, H., \& Leydesdorff, L. (1995). The Triple Helix - University-IndustryGovernment Relations: A Laboratory for Knowledge-Based Economic Development. EASST Review, 14, 14-19. Retrieved from http://www.leydesdorff.net/thi/index.htm. Etzkowitz, H., \& Leydesdorff, L. (2000). The dynamics of innovation: from National Systems and "Mode 2" to a Triple Helix of university-industry-government relations. Research Policy, 29(2), 109-123. doi:doi: DoI: 10.1016/Soo48-7333(99)ooo55-4.

Etzkowitz, H., \& Viale, R. (2010). Polyvalent Knowledge and the Entrepreneurial University: A Third Academic Revolution? Critical Sociology, 36(4), 595-6o9. doi:10.1177/ o896920510365921. 
Etzkowitz, H., \& Zhou, C. (2017). The Triple Helix: University-Industry-Government Innovation and Entrepreneurship (Second ed.). Abingdon: Routledge.

Gibbons, M., Limoges, C., Nowotny, H., Schwartzman, S., Scott, P., \& Trow, M. (1994). The new production of knowledge. The dynamics of science and research in contemporary societies. London: Sage.

Ivanova, I., Strand, Ø., Kushnir, D., \& Leydesdorff, L. (2015). The Efficiency of TripleHelix Relations in Innovation Systems: Measuring the Connection between a Country's Net Income and Its Knowledge Base. Higher School of Economics Research Paper No. \#WP BRP 54/STI/2015. Retrieved from https://papers.ssrn.com/sol3/papers .cfm?abstract_id=2700627\#.

Kalecki, M. (1954). Theory of Economic Dynamics - An Essay on Ciclical and Long-Run Changes in Capitalist Economy. London: George Allen \&Unwin.

Kuhn, T. (2012). The Structure of Scientific Revolutions: 5oth Anniversary Edition. Chicago: University of Chicago Press.

Leydesdorff, L. (2000). The triple helix: an evolutionary model of innovations. Research Policy, 29(2), 243-255. doi:10.1016/soo48-7333(99)ooo63-3.

Leydesdorff, L. (2003). The mutual information of university-industry-government relations: An indicator of the Triple Helix dynamics. Scientometrics, $58(2), 445^{-467}$. doi:10.1023/a:1026253130577.

Leydesdorff, L. (2008). Configurational Information as Potentially Negative Entropy: The Triple Helix Model. Entropy, 10(4), 391-410. doi:10.339o/e10o40391.

Leydesdorff, L. (2012). The Triple Helix, Quadruple Helix, ..., and an $<\mathrm{i}>\mathrm{N}$-Tuple of Helices: Explanatory Models for Analysing the Knowledge-Based Economy? Journal of the Knowledge Economy, 3(1), 25-35. doi:10.1007/s13132-011-0049-4.

Leydesdorff, L., \& Meyer, M. (2003). The Triple Helix of university-industry-government relations. Scientometrics, 58(2), 191-203. doi:10.1023/a:1026276308287.

Leydesdorff, L., \& Park, H. W. (2014). Can synergy in Triple Helix relations be quantified? A review of the development of the Triple Helix indicator. 1(1), 1. doi:https:// doi.org/10.1186/s406o4-014-0004-z.

Malik, T. H., Kabiraj, S., \& Huo, C. (2021). Chinese Universities Mobilise FDI and DDI for the City's Innovativeness in the ICT Sector. Triple Helix, 1-35. doi:10.1163/ 21971927-bja1oo17.

Marshall, A. (1960). Principles of Economics: An Introductory Volume (8th Edition ed.): Palgrave MacMillan.

Olvera, C., Piqué, J. M., Cortés, U., \& Nemirovsky, M. (2020). Evaluating UniversityBusiness Collaboration at Science Parks: a Business Perspective. Triple Helix, 1-41. doi:10.1163/21971927-bja10oo7.

Perez, C. (2010). Technological revolutions and techno-economic paradigms. Cambridge Journal of Economics, 34(1), 185-202. doi:10.1093/cje/bepo51. 
Piqué, J. M., Berbegal-Mirabent, J., \& Etzkowitz, H. (2020). The Role of Universities in Shaping the Evolution of Silicon Valley's Ecosystem of Innovation. Triple Helix, 7(2), 1-45. doi:10.1163/21971927-bja1ooog.

Ranga, M., \& Etzkowitz, H. (2013). Triple Helix Systems: An Analytical Framework for Innovation Policy and Practice in the Knowledge Society. , 27(4), Special Issue (August 2013). Industry and Higher Education, 27(4), 237-262.

Röpke, J. (1998). The Entrepreneurial University: Innovation, Academic Knowledge Creation and Regional Development in a Globalised Economy. Retrieved from Marburg, Germany.

Rothgang, M., \& Lageman, B. (2021). Kairos in Innovation Policy. Triple Helix, $1-51$. doi:10.1163/21971927-bja1oo18.

Slaughter, S., \& Leslie, L. L. (1997). Academic capitalism : politics, policies, and the entrepreneurial university. Baltimore, Md. ; London: Johns Hopkins University Press.

Virkkala, S., \& Mariussen, Å. (2021). Networks of Innovation: Measuring Structure and Dynamics between and within Helices, Regions and Spatial Levels. Empirical Evidence from the Baltic Sea Region. Triple Helix, 1-47. doi:10.1163/21971927-bja1oo19. 